\title{
Influence of the Atmospheric Precipitation Phase Composition on Seasonal Evolution of Snow-Ice Cover in the Taganrog Bay Apex
}

\author{
D. D. Zavyalov \\ Marine Hydrophysical Institute of RAS, Sevastopol, Russian Federation \\ zavyalov.dd@mhi-ras.ru
}

\begin{abstract}
Purpose. The present study is aimed at assessing influence of the atmospheric precipitation phase composition upon simulation of seasonal evolution of ice thickness in the Taganrog Bay apex.

Methods and Results. The ice regime characteristics in the northeastern part of the Taganrog Bay were studied by means of the ice cover thermodynamic model. The observational data on the basic meteorological parameters obtained every 3 hours per day at the meteorological station Taganrog were used as a meteorological forcing. The simulations included the static and dynamic methods for dividing total prognostic precipitation into the liquid and solid fractions. The first method implied presence of the temperature threshold, below which all the precipitations were classified as snow and above which - as rain. The second one took into account gradual transition from rain to snow within the preset temperature interval. For the winters differing in precipitation amount during the ice period, the comparative analysis of the results of simulating the sea ice thickness seasonal evolution was done, and the model sensitivity to choosing the method for determining the portions of the solid and liquid phases was assessed. Simulation veracity was defined through comparison of the sea ice thickness model values with the actual ones from the ESIMO ice maps for the winter seasons 2007/2008-2010/2011.

Conclusions. It is shown that the results obtained by application of the S-like dependence of a snow portion in the atmospheric precipitation within the temperature transition interval, proved to be the most justified from the viewpoint of the root-mean-square deviation and correlation coefficient optimal values. The minimal errors in reproducing the ice thickness seasonal evolution are obtained at the temperature threshold close to $2{ }^{\circ} \mathrm{C}$ and the width of the temperature transition interval $5-9{ }^{\circ} \mathrm{C}$. The best results for the low-snow winters are obtained due to applying the static method for determining a precipitation phase.
\end{abstract}

Keywords: sea ice, thermodynamics, ice thickness, atmospheric precipitation, rain, snow, Sea of Azov.

Acknowledgements: the investigation was carried out within the framework of the state task on theme No. 0827-2019-0003 "Fundamental studies of oceanic processes conditioning state and evolution of marine environment being affected by natural and anthropogenic factors, based on observation and modeling methods".

For citation: Zavyalov, D.D., 2020. Influence of the Atmospheric Precipitation Phase Composition on Seasonal Evolution of Snow-Ice Cover in the Taganrog Bay Apex. Physical Oceanography, [e-journal] 27(2), pp. 387-396. doi:10.22449/1573-160X-2020-2-126-141

DOI: $10.22449 / 1573-160 X-2020-2-126-141$

(C) D. D. Zavyalov, 2020

(C) Physical Oceanography, 2020

\section{Introduction}

Ice cover is an important component of the Sea of Azov hydrological regime because, depending on the severity of the winter period, both partial and complete freezing are observed. Sea ice limits the economic activity in the region, significantly complicates the conditions for navigation and poses a real danger to hydraulic structures. The sea ice evolution is determined by the thermal and dynamic regimes of the atmosphere and the aquatic environment; at the same time, 
the ice cover itself has a significant effect on the heat fluxes between these environments. An essential role in the sea ice formation and development is played by atmospheric precipitation. Snow accumulates on the ice surface, and precipitation in the form of rain falling on the snow is absorbed by it, changing the snow cover density and albedo. Liquid precipitation enhances the melting of snow and ice even in those cases when the rain temperature is just slightly higher than $0{ }^{\circ} \mathrm{C}$. The mentioned features of the precipitation effect on the snow-ice cover should be correctly assessed and taken into account when calculating the sea ice characteristics. Precipitation is one of the most variable in time and space meteorological phenomena, and information on their phase composition is an important synoptic characteristic of the region. A considerable amount of mixed precipitation falls on the Sea of Azov surface even in the cold season, and the number of days with rain in winter can exceed the number of days with snow [1]. The complexity of observations and the paucity of direct measurements of both the Sea of Azov snow-ice cover and the phase nature of precipitation significantly complicate the study of winter thermodynamics of this basin. Uncertainty arising in calculating the thickness of the sea snow-ice cover can be largely associated with inaccuracies in determining the phase composition of precipitation.

A review of existing methods for determining the phase composition of precipitation is presented in [2]. Near-surface air temperature can be used as one of possible criteria for the separation of precipitation into phases (rain/snow). Forecasts of air temperature at the moment are quite reliable. In addition, this parameter lends itself well to interpolation, as well as extrapolation in the region with no observations.

In the models of snow cover dynamics based on the determination of the precipitation phase composition by the value of near-surface air temperature, static and dynamic methods for separating precipitation into phases (rain/snow) are used. In the static method the criterion for dividing into liquid and solid precipitation is the threshold air temperature [3] below which all precipitation is classified as snow, above - as rain. The dynamic precipitation separation method takes into account the gradual change in the proportion of rain and snow in some temperature range [4 - 7]. Such dependencies are not universal and have a pronounced regional character. The threshold value and the boundaries of temperature range, as well as the nature of the dependence of rain/snow percentage on temperature, are determined from meteorological data or during the calibration of model parameters. Since there are very few field and prognostic data on the phase composition of precipitation over the Sea of Azov, the problem is to compare the results of modeling the seasonal thermal dynamics of the sea ice thickness using various methods for determining the fraction of solid and liquid phases in total precipitation. The reliability of the simulation results was assessed by comparing the simulated and actual values of the sea ice thickness taken from ice maps published by the Unified State System of Information on the World Ocean * (ESIMO).

* ESIMO. [online] Available at: http://esimo.ru/portal/ [Accessed: 04 September 2019].

PHYSICAL OCEANOGRAPHY VOL. 27 ISS. 2 (2020) 


\section{Thermodynamic model of snow-ice cover}

The thermal evolution of snow-ice cover is described by the locally onedimensional thermodynamic model [8-12]. The heat distribution in the layers of snow and ice is determined by heat conduction equations

$$
(\rho c)_{\mathrm{i}, \mathrm{s}} \frac{\partial T_{\mathrm{i}, \mathrm{s}}(z, t)}{\partial t}=\frac{\partial}{\partial z}\left(k_{\mathrm{i}, \mathrm{s}} \frac{\partial T_{\mathrm{i}, \mathrm{s}}(z, t)}{\partial z}\right)-\frac{\partial I_{\mathrm{i}}(z, t)}{\partial z} .
$$

Boundary conditions for the equations (1) at the upper $(z=0)$ and lower $(z=$ $\left.=h_{\mathrm{i}}(t)\right)$ surfaces of snow-ice cover express the conditions of thermodynamic equilibrium

$$
\begin{array}{ll}
-k_{\mathrm{i}, \mathrm{s}} \frac{\partial T_{\mathrm{i}, \mathrm{s}}}{\partial \mathrm{z}}=F_{\mathrm{t}}\left(T_{\mathrm{sfc}}\right), & \mathrm{z}=0, \\
-k_{\mathrm{i}} \frac{\partial T_{\mathrm{i}}}{\partial \mathrm{z}}=F_{\mathrm{b}}\left(T_{\mathrm{f}}, T_{\mathrm{w}}\right), T_{\mathrm{i}}=T_{\mathrm{f},} & \mathrm{z}=h_{\mathrm{i}}(t) .
\end{array}
$$

In the thickness of the ice plate and the snow layer the temperature distribution is considered linear, on the snow-ice interface the conditions of heat flux and temperature continuity are satisfied

$$
k_{\mathrm{s}} \frac{\partial T_{\mathrm{s}}}{\partial \mathrm{z}}=k_{\mathrm{i}} \frac{\partial T_{\mathrm{i}}}{\partial \mathrm{z}}, \quad T_{\mathrm{s}}=T_{\mathrm{i}}, \quad z=h_{\mathrm{s}}(t)
$$

At moving interfaces between different phases of a substance, the law of energy conservation during phase transitions is fulfilled

$$
\begin{array}{ll}
-\rho_{\mathrm{i}, \mathrm{s}} L_{\mathrm{fi}, \mathrm{s}} \frac{\partial h_{\mathrm{i}, \mathrm{s}}}{\partial t}=F_{\mathrm{t}}\left(T_{\mathrm{mi}, \mathrm{s}}\right)+k_{\mathrm{i}, \mathrm{s}} \frac{\partial T_{\mathrm{i}, \mathrm{s}}}{\partial \mathrm{z}}, & \mathrm{z}=0, \\
-\rho_{\mathrm{i}} L_{\mathrm{fi}} \frac{\partial h_{\mathrm{i}}}{\partial t}=F_{\mathrm{b}}\left(T_{\mathrm{f}}, T_{\mathrm{w}}\right)-k_{\mathrm{i}} \frac{\partial T_{\mathrm{i}}}{\partial z}, & z=h_{\mathrm{i}}(t) .
\end{array}
$$

If the snow-ice cover is absent, then the heating or cooling of mixed quasihomogeneous water layer takes place:

$$
\frac{\partial T_{\mathrm{w}}}{\partial t} \rho_{\mathrm{w}} c_{\mathrm{w}} h_{\mathrm{w}}=F_{\mathrm{b}}-F_{\mathrm{t}}-v \rho_{\mathrm{s}} L_{\mathrm{fs}}, \quad \mathrm{z} \in\left[0, h_{\mathrm{w}}\right]
$$

The initial water temperature and salinity are considered to be set:

$$
T_{\mathrm{w}}(\mathrm{z}, 0)=T_{\mathrm{w} 0}, \quad S_{\mathrm{w}}(\mathrm{z}, 0)=S_{\mathrm{w} 0} \quad \mathrm{z} \in\left\lfloor 0, h_{\mathrm{w}}\right\rfloor .
$$


Here $t$ is time; $z$ is vertical coordinate, axis is directed downward from the upper surface of the snow-ice cover $(z=0) ; \rho$ is a density; $h$ is a thickness; $T$ is a temperature; $S$ is salinity; $c$ is heat capacity; $k$ is thermal conductivity; $L_{\mathrm{f}}$ is heat of fusion; $I_{\mathrm{i}}$ is a solar radiation penetrating the ice; $T_{\mathrm{sfc}}, T_{\mathrm{mi}, \mathrm{s}}, T_{\mathrm{f}}$ are a temperature on the upper surface of snow-ice cover, a temperature of snow/ice melting and a temperature of water freezing, respectively; $v$ is a rate of solid precipitation falling; $F_{\mathrm{t}}$ is a heat flux from the atmosphere through the upper boundary of snowice cover; $F_{\mathrm{b}}$ is a heat flux from the water to the lower ice boundary. Hereinafter, the indices i, s, w and a refer to the parameters of ice, snow, water and atmosphere, respectively. Note that equation (1) for snow is solved under the assumption that solar radiation does not penetrate deep into the snow and is completely absorbed in the uppermost layer. In the presence of snow, the heat conduction equation for ice is written without taking into account penetrating radiation.

The rate of snow-ice cover thermal evolution depends on the difference between the heat flux from the atmosphere through its upper boundary and the heat flux from the water to its lower boundary. At the upper boundary, the heat flux $F_{\mathrm{t}}$ consists of sensible heat flux $F_{\mathrm{s}}$ and latent heat flux $F_{\mathrm{l}}$, which are determined by the integral aerodynamic formulas [8]

$$
F_{\mathrm{s}}=c_{\mathrm{pa}} \rho_{\mathrm{a}} \mathrm{St}_{\mathrm{a}}\left(T_{\mathrm{sfc}}-T_{\mathrm{a}}\right), \quad F_{1}=L \rho_{\mathrm{a}} \mathrm{Da} V_{\mathrm{a}}\left(q_{0}\left(T_{\mathrm{sfc}}\right)-q_{\mathrm{a}}\left(T_{\mathrm{a}}\right)\right),
$$

long-wave $R$ and short-wave $F$ surface radiation balances [8]:

$$
\begin{gathered}
R=4 \lambda \sigma T_{\mathrm{sfc}} T_{\mathrm{a}}^{3}-\lambda \sigma T_{\mathrm{a}}^{4}\left(3,765+0,22 N^{3}\right), \\
F=F_{0}(1-\eta N)(1-\alpha)\left(1-i_{0}\right), \\
F_{0}=S \cos ^{2} z_{\Theta}\left(\left(\cos z_{\Theta}+2,7\right) e \cdot 10^{-5}+1,085 \cos z_{\Theta}+0,1\right)^{-1},
\end{gathered}
$$

as well as heat fluxes related to the processes of cooling and possible subsequent crystallization of liquid precipitation

$$
F_{\mathrm{m}}=c_{\mathrm{w}} P_{\text {rain }}\left(T_{\mathrm{a}}-273,15\right)+P_{\text {rain }} L_{\mathrm{fi}} .
$$

Here $e$ is water vapor pressure; $V_{\text {a }}$ is a wind velocity; $P_{\text {rain }}$ is an amount of precipitation in liquid phase; specific air humidity at $2 \mathrm{~m}$ height $q_{\mathrm{a}}=\left(0,622 e_{0} f / P_{\mathrm{a}}\right) \cdot 10^{a_{1} T_{a} /\left(b_{1}+T_{a}\right)}$ and at the upper boundary of the snow-ice cover $q_{0}=\left(0,622 e_{0} / P_{\mathrm{a}}\right) \cdot 10^{a_{1} T_{s f c} /\left(b_{1}+T_{s f c}\right)} ; a_{1}=9.5 ; b_{1}=265.5 \mathrm{~K} ; P_{\mathrm{a}}$ is an atmospheric air pressure; $e_{0}=611 \mathrm{hPa}$ is a pressure of saturated water vapor at $0{ }^{\circ} \mathrm{C} ; c_{\mathrm{pa}}=$ $=10^{3} \mathrm{~J} /(\mathrm{kg} \cdot \mathrm{K})$ is a heat capacity of air at constant pressure; $f$ is relative humidity; $L$ is a specific heat of sublimation; $\sigma$ is the Stefan - Boltzmann constant; $\lambda, \alpha$ is emissivity and albedo of underlying surface; $N$ is an amount of total cloudiness; $\eta$ is an empirical coefficient; $i_{0}$ is a coefficient determining a part of short-wave radiation that penetrates the snow-ice layer and is evenly distributed over its thickness; $F_{0}$ is an incoming short-wave solar radiation for a cloudless sky; $S$ is solar constant; $z_{\Theta}$ is the zenith angle of the Sun. 
The calculation of $F_{\mathrm{s}}$ and $F_{1}$ was carried out with constant values of the empirical coefficients of heat and moisture exchange $\mathrm{St}=\mathrm{Da}=1.7 \cdot 10^{-3}$. The snow albedo was parameterized similarly to that presented in ECHAM5 general atmospheric circulation model [13], and the albedo calculation scheme for snowless sea ice was taken from CCSM2 sea ice block of the National Research Center climatic model [14].

The heat flux from the water to the ice lower surface was determined as

$$
F_{\mathrm{b}}=c_{\mathrm{w}} \rho_{\mathrm{w}} C_{\mathrm{tb}}\left(T_{\mathrm{w}}-T_{\mathrm{f}}\right),
$$

where $C_{\mathrm{tb}}=10^{-3} \mathrm{~m} / \mathrm{s}$ is a turbulent exchange coefficient.

The model of snow cover accumulating on the sea ice surface is based on the schematization of processes that make the greatest contribution to the formation of physical and thermophysical characteristics of snow [15]. The dependence of fresh snow density $\rho_{\mathrm{s} 0}$ on the temperature of the atmosphere surface layer was determined using the CLASS algorithm [16], and the wind compaction of snow was parameterized as $\rho_{\mathrm{s}}=\max \left(\rho_{\mathrm{s} 0} ; 20 V_{\mathrm{a}}\right), \mathrm{kg} / \mathrm{m}^{3}$ based on the assumption [17] that its density would increase by $20 \mathrm{~kg} / \mathrm{m}^{3}$ with increasing wind velocity for every $1 \mathrm{~m} / \mathrm{s}$.

Due to melting snow or rain, the water that seeps deep into the snow layer and leads to an increase in its density is formed. The maximum amount of water that a snow layer may contain is determined by its water retaining capacity $\Theta_{\max }$ [18].

If the amount of liquid water $\Theta_{w}$ in the snow layer exceeds $\Theta_{\max }$, then its excess moves to the lower layer or forms a water runoff on the snow - ice interface where it crystallizes if $T_{\mathrm{s}}<T_{\mathrm{mi}}$. The density of each layer is calculated taking into account the amount of water contained in the liquid and solid phases. The thermal conductivity of the snow column (the set of snow layers) is defined as $k_{\mathrm{s}}=9,165 \cdot 10^{-2}-3,814 \cdot 10^{-4} \rho_{\mathrm{s}}+2,905 \cdot 10^{-6} \rho_{\mathrm{s}}^{2}$ [19], where $\rho_{\mathrm{s}}$ is the integral density of the column.

The temperature of the snow-ice surface $T_{\text {sfc }}$ (assuming a linear temperature profile in the snow and ice layer) is calculated using the heat balance equations (2) and the heat flux continuity at the snow - ice interface (4):

$$
k_{\mathrm{i}} \frac{T_{\mathrm{f}}-T_{\mathrm{sfc}}}{h_{\mathrm{i}}+\left(k_{\mathrm{i}} / k_{\mathrm{s}} h_{\mathrm{s}}\right)}-F_{\mathrm{t}}\left(T_{\mathrm{sfc}}\right)=0, z=0 .
$$

If $T_{\mathrm{sfc}}>T_{\mathrm{mi}, \mathrm{s}}$, then we assume that $T_{\mathrm{sfc}}=T_{\mathrm{mi}, \mathrm{s}}$ and the excess heat is spent on snow/ice melting. The rate of snow/ice thickness variation and the formation of melt water is determined by equation (5).

The ice cover buoyancy is small and its congestion occurs if the snow cover height reaches approximately $40 \%$ of the ice thickness [20], therefore the process of turning snow into ice is possible when the snow - ice interface is below the water level. In this case, we assume that snow below the water level turns into ice. The presented thermodynamic model does not take into account the features related to the formation of melt water (puddles) on the ice cover surface [21, 22]. During the winter seasons considered in the paper, the conditions for the formation 
of melt water on the ice surface may arise. However, in order to carry out a reliable assessment of the effect of puddles on the ice cover thickness seasonal evolution in the Sea of Azov, additional studies are required.

To assess the forecast of the ice thickness seasonal variation using different criteria for determining the phase composition of precipitation, the following were analyzed:

- the value of root-mean-square deviation $h_{\mathrm{i}}$ from $h_{\mathrm{obs}}: \sigma=\sqrt{\sum_{l} \frac{E_{t}{ }^{2}}{l}}$, where $E_{t}=h_{\mathrm{i}}-h_{\mathrm{obs}}$ is a model error;

- correlation coefficient: $K=\frac{\sum_{l}\left(h_{\mathrm{obs}}-\bar{h}_{\mathrm{obs}}\right)\left(h_{\mathrm{i}}-\bar{h}_{\mathrm{i}}\right)}{\sqrt{\sum_{l}\left(h_{\mathrm{obs}}-\bar{h}_{\mathrm{obs}}\right)^{2} \sum_{l}\left(h_{\mathrm{i}}-\bar{h}_{\mathrm{i}}\right)^{2}}}$, where $\bar{h}_{\mathrm{obs}}$ is

an ice thickness average over the computational period (according to measurement data), $\bar{h}_{\mathrm{i}}$ is an ice thickness average over the computational period (according to the model data);

$$
\begin{aligned}
& \text { - determination coefficient } R^{2}=1-\frac{\sum_{l} E_{t}^{2}}{\sum_{l}\left(h_{i}-h_{i}\right)^{2}} ; \\
& \text { - Theil mismatch coefficient } U=\frac{\sqrt{\sum_{l} E_{t}^{2}}}{\sqrt{\sum_{l} h_{\mathrm{obs}}^{2}}+\sqrt{\sum_{l} h_{i}^{2}}} \text {, where } l \text { is a number of }
\end{aligned}
$$

steps in which the measured ice thickness corresponding to computational time step differed from zero.

\section{Numerical modeling results}

Based on the constructed thermodynamic model, the numerical experiments for studying the effect of the precipitation phase composition on the reconstruction of ice thickness seasonal evolution at the edge of the Taganrog Bay were carried out. Variants for determining the snow portion $\operatorname{Pr}_{\text {snow }}\left(t_{\mathrm{a}}\right)$ in the total precipitation are presented in Table. 1 . The first variant involves an abrupt transition from snow to rain at a threshold air temperature $T t$. In variants 2 and 3, based on the linear and S-like dependencies $\operatorname{Pr}_{\text {snow }}\left(t_{\mathrm{a}}\right)$, respectively, the two variables most suitable for a given region were selected: air temperature $T_{50}$, at which $50 \%$ of the precipitation is considered snow, and the width of the temperature range $\mathrm{Tr}$ where mixed precipitation is observed. For variants $1-3$, a series of calculations where $T t$ (variant 1 ) and $T_{50}$ (variants 2,3 ) varied in the interval $-2 \ldots 3{ }^{\circ} \mathrm{C}$ with $1{ }^{\circ} \mathrm{C}$ step and $\mathrm{Tr}$ - in the interval $13 \ldots 1{ }^{\circ} \mathrm{C}$ with $2{ }^{\circ} \mathrm{C}$ step was performed. In variant 4 , a semi-empirical precipitation separation formula [6], obtained on the basis of the analysis of data collected during 1977-2007 period was applied. 
It was assumed that for the regions located above the ocean the temperature $T_{50}$ is $1.9{ }^{\circ} \mathrm{C}$, the transition temperature range is within $-3 \ldots 6{ }^{\circ} \mathrm{C}\left(\operatorname{Tr}=9{ }^{\circ} \mathrm{C}\right)$ range and the ratio $\operatorname{Pr}_{\text {snow }}\left(t_{\mathrm{a}}\right)$ is represented using a hyperbolic tangent with an angle tilt close to 0.4 . Variant 5 reflects the results of studies of relative air humidity $f$ effect on the temperature $T_{50}$ and $T_{50}$ and $\operatorname{Tr}$ spatial variability in the Northern Hemisphere [7]. Based on the processing of 29-year (1978-2007) set of observational data, 6 variation ranges of relative air humidity $f$ were proposed, for which $T_{50}(f)$ values were determined. Semi-empirical dependencies $\operatorname{Pr}_{\text {snow }}\left(t_{\mathrm{a}}\right)$ for variants 4, 5 are given in Fig. 1.

Table 1

Variants of the snow portion $\operatorname{Pr}_{\text {snow }}\left(t_{\mathrm{a}}\right)$ dependences in total precipitation

\begin{tabular}{|c|c|c|}
\hline $\begin{array}{l}\text { Variant } \\
\text { number }\end{array}$ & \begin{tabular}{|c|} 
Type of \\
dependence, \\
source
\end{tabular} & Snow portion $P r_{\text {snow }}\left(t_{\mathrm{a}}\right)$ in total precipitation \\
\hline 1 & $\begin{array}{c}\text { Static } \\
\operatorname{metod}[3]\end{array}$ & $\begin{array}{l}\operatorname{Pr}_{\text {snow }}\left(t_{\mathrm{a}}\right)=1, \quad t_{\mathrm{a}} \leq T t \\
\operatorname{Pr}_{\text {snow }}\left(t_{\mathrm{a}}\right)=0, \quad t_{\mathrm{a}}>T t \\
T t-\text { threshold temperature, }{ }^{\circ} \mathrm{C}\end{array}$ \\
\hline 2 & $\begin{array}{c}\text { Linear } \\
\text { transition, } \\
{[4]}\end{array}$ & $\begin{array}{ll}\operatorname{Pr}_{\text {snow }}\left(t_{\mathrm{a}}\right)=1, & t_{a}<\left(T_{50}-0.5 T r\right) \\
\operatorname{Pr}_{\text {snow }}\left(t_{\mathrm{a}}\right)=\frac{T_{50}+0.5 \operatorname{Tr}-t_{a},}{\operatorname{Tr}} & \left(T_{50}-0.5 T r\right) \leq t_{a} \leq\left(T_{50}+0.5 T r\right) \\
\operatorname{Pr}_{\text {snow }}\left(t_{\mathrm{a}}\right)=0, & t_{a}>\left(T_{50}+0.5 T r\right) \\
\operatorname{Pr}_{\text {snow }}\left(t_{\mathrm{a}}\right)=0.5 ; & t_{a}=T_{50} \\
\operatorname{Tr}-\text { width of transition range, }{ }^{\circ} \mathrm{C} & \end{array}$ \\
\hline 3 & $\begin{array}{c}\text { S-like } \\
\text { transition, } \\
\text { S. W. } \\
\text { Kienzle [5] }\end{array}$ & $\begin{array}{l}P r_{\text {snow }}\left(t_{\mathrm{a}}\right)=1-P r_{\text {rain }}\left(t_{\mathrm{a}}\right) \\
P r_{\text {rain }}\left(t_{\mathrm{a}}\right)=5\left(\frac{t_{a}-T_{50}}{1.4 T r}\right)^{3}+6.76\left(\frac{t_{a}-T_{50}}{1.4 T r}\right)^{2}+3.19\left(\frac{t_{a}-T_{50}}{1.4 T r}\right)+0.5 \\
t_{a}<T_{50} \\
P r_{\text {rain }}\left(t_{\mathrm{a}}\right)=5\left(\frac{t_{a}-T_{50}}{1.4 T r}\right)^{3}-6.76\left(\frac{t_{a}-T_{50}}{1.4 T r}\right)^{2}+3.19\left(\frac{t_{a}-T_{50}}{1.4 T r}\right)+0.5 \\
t_{a} \geq T_{50}\end{array}$ \\
\hline 4 & $\begin{array}{l}\text { S-like } \\
\text { transition, } \\
\text { A. Dai [6] }\end{array}$ & $\begin{array}{l}P r_{\text {snow }}\left(t_{\mathrm{a}}\right)=a\left[\tanh \left(b\left(t_{a}-c\right)\right)-d\right] \\
a=47.1823 ; b=0.4003 ; c=2.1735 ; d=1.0255\end{array}$ \\
\hline 5 & $\begin{array}{c}\text { S-like } \\
\text { transition, } \\
\text { K. Jennings } \\
{[7]}\end{array}$ & $\begin{array}{l}P r_{\text {snow }}=P r_{\text {snow }}\left(t_{\mathrm{a}}, f\right) \\
T_{50}: 4.5^{\circ} \mathrm{C}(0.4<f \leq 0.5), \quad 3.7^{\circ} \mathrm{C}(0.5<f \leq 0.6), \\
2.8^{\circ} \mathrm{C}(0.6<f \leq 0.7), \quad 1.4^{\circ} \mathrm{C}(0.8<f \leq 0.9), \quad 0.7^{\circ} \mathrm{C}(0.9<f \leq 1) \\
\left.2.2^{\circ} \mathrm{C}(0.7<f \leq 0.8), \quad{ }^{\circ}\right)\end{array}$ \\
\hline
\end{tabular}




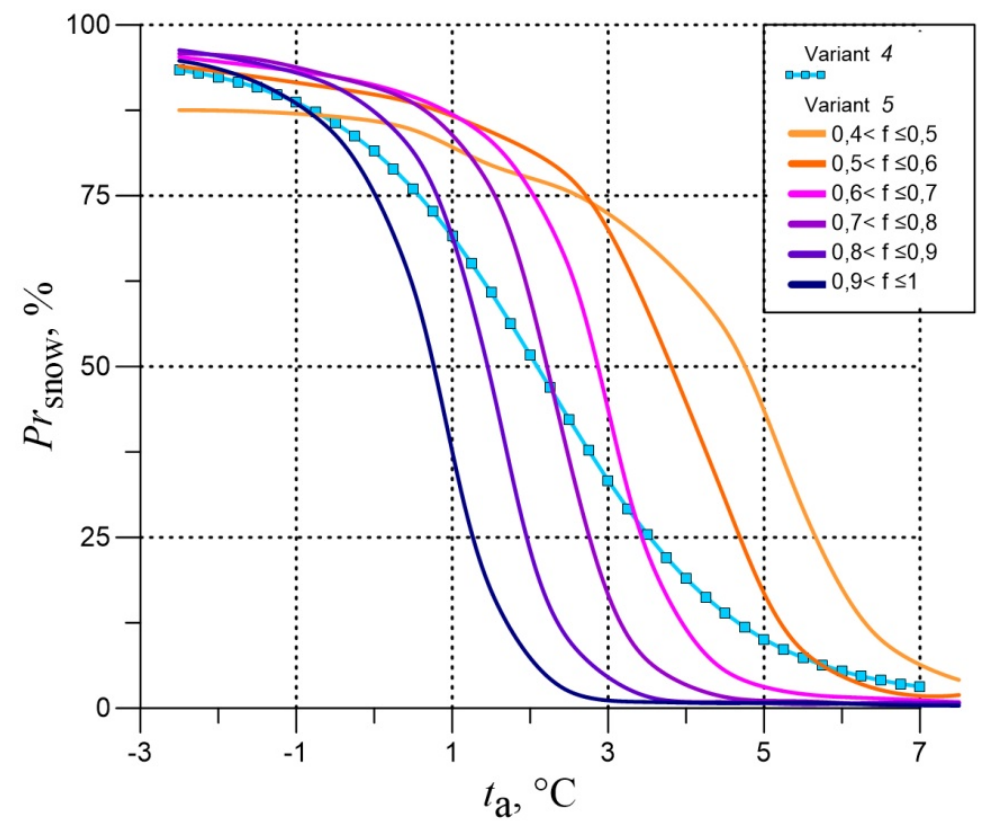

F i g. 1. Dependence of the snow portion $P r_{\text {snow }}\left(t_{\mathrm{a}}\right)$ in total precipitation upon the surface air temperature $t_{\mathrm{a}}$

The data of eight-term observations of the main meteorological parameters of RIHMI-WDC ${ }^{* *}$ at the Taganrog weather station were used as external forcing (surface temperature, atmospheric pressure, humidity, total cloud cover, wind velocity and total precipitation). In Fig. 2 the distribution of daily average air temperature at $2 \mathrm{~m}$ height (solid lines) and total daily precipitation (bar graphs) are represented. The amount of actual precipitation from the date of the first ice formation to the date of complete final ice clearing [23] for the ice seasons 2007/08-2010/11 amounted to 103, 144, 295 and $61 \mathrm{~kg} / \mathrm{m}^{2}$, respectively. The precipitation rate calculated for the same ice seasons according to the monthly average climatic values *** was $159,111,133$ and $96 \mathrm{~kg} / \mathrm{m}^{2}$. Thus, according to the amount of precipitation, the seasons 2007/08 and 2010/11 can be attributed to arid (low-snow) seasons, 2008/09 season is close to normal and in 2009/10 the precipitation amount is significantly higher than the climatic norm.

\footnotetext{
** RIHMI-WDS. [Hydrometeorological Data], 2019. [online] Available at: http://meteo.ru [Accessed: 04 September 2019].

*** Merkel, A., 2019. Climatic Data for Cities around the World. [online] Available at: https://ru.climate-data.org [Accessed: 23 October 2019].
} 

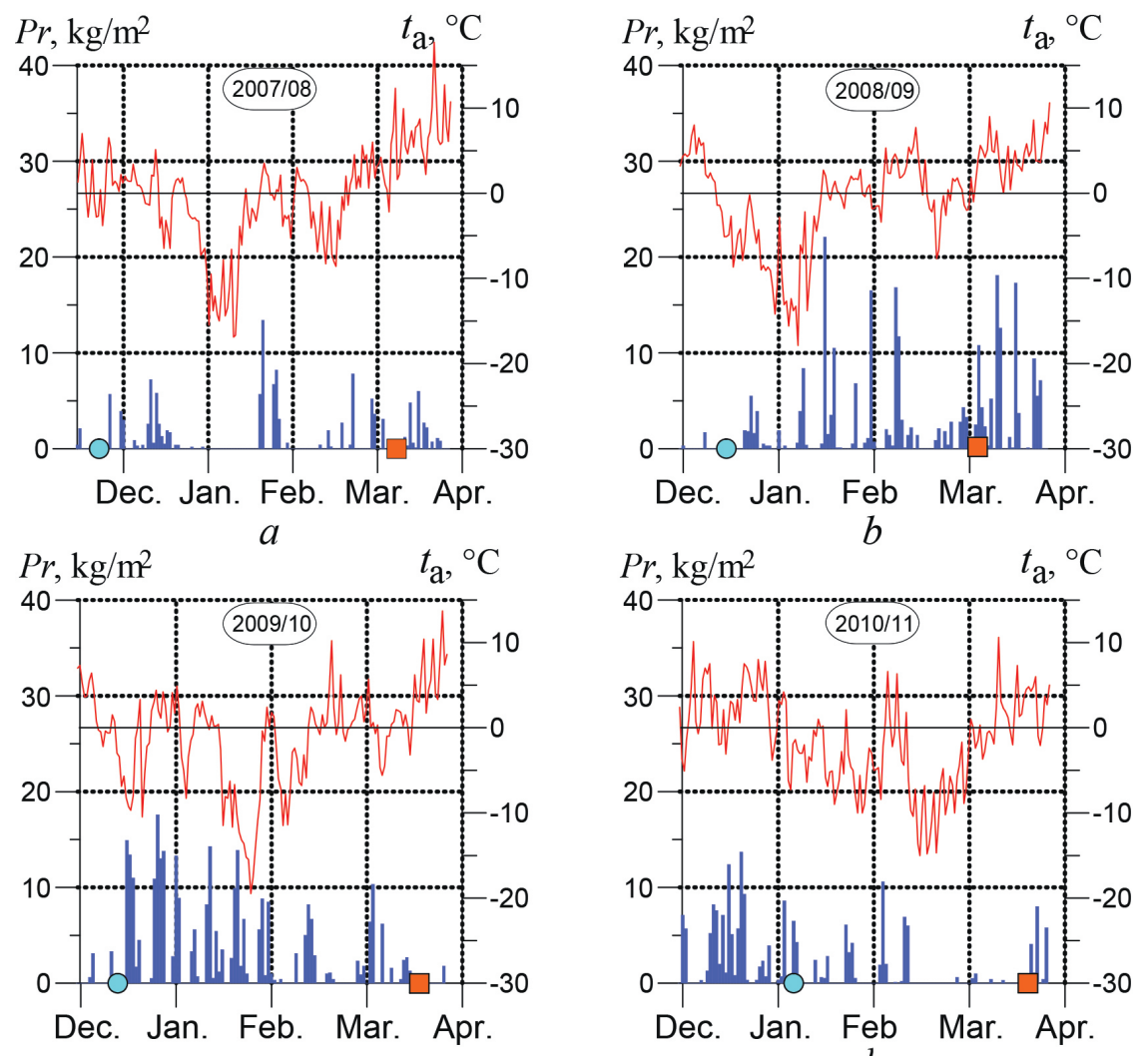

$c$

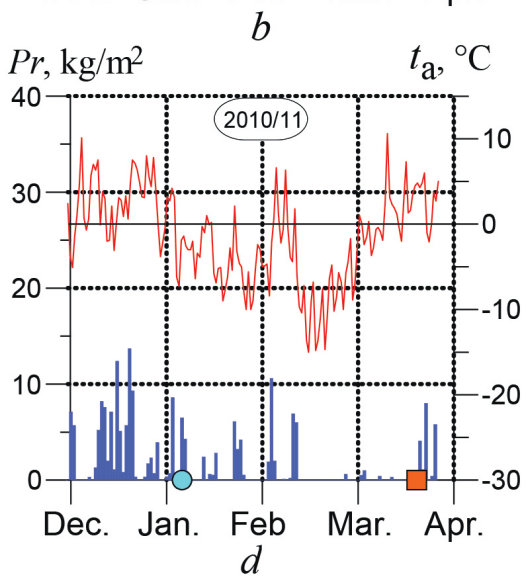

- the first ice formation

$\square$ - final purification of ice

F i g. 2. Distribution of the mean daily air temperature at the $2 \mathrm{~m}$ height (solid lines) and total daily precipitation (bar graphs) at the Taganrog meteorological station based on the RIHMI-WDC data (the dates here and in Fig. 5 related to the ice regime basic elements, are from [23])

Model calculations began about a month before the start of sustainable ice formation. The model time step is $3 \mathrm{~h}$. The monthly average climatic temperature and water salinity were set as initial conditions [24]. The temperature of cooled surface (snow, ice, water) was subsequently calculated from the heat balance equations.

In Fig. 3 the amplitudes of root-mean-square errors $\sigma$ in forecasting the ice thickness seasonal evolution for the dependencies $\operatorname{Pr}_{\text {snow }}\left(t_{\mathrm{a}}\right)$ determined according to variants $1-5$ are given. The segments combine the minimum $\sigma_{\min }$ and the maximum $\sigma_{\max }$ error values obtained in a series of calculations at varying temperature $T t$ (for variant 1 ), temperature $T_{50}$ (for variants 2,3 ) and the width of the transition range $T r$. The numbers in the circles indicate the values of $T t$ temperatures (for variant 1 ) and $T_{50}$ (for variants 2,3 ) at which $\sigma_{\min }$ was realized. 

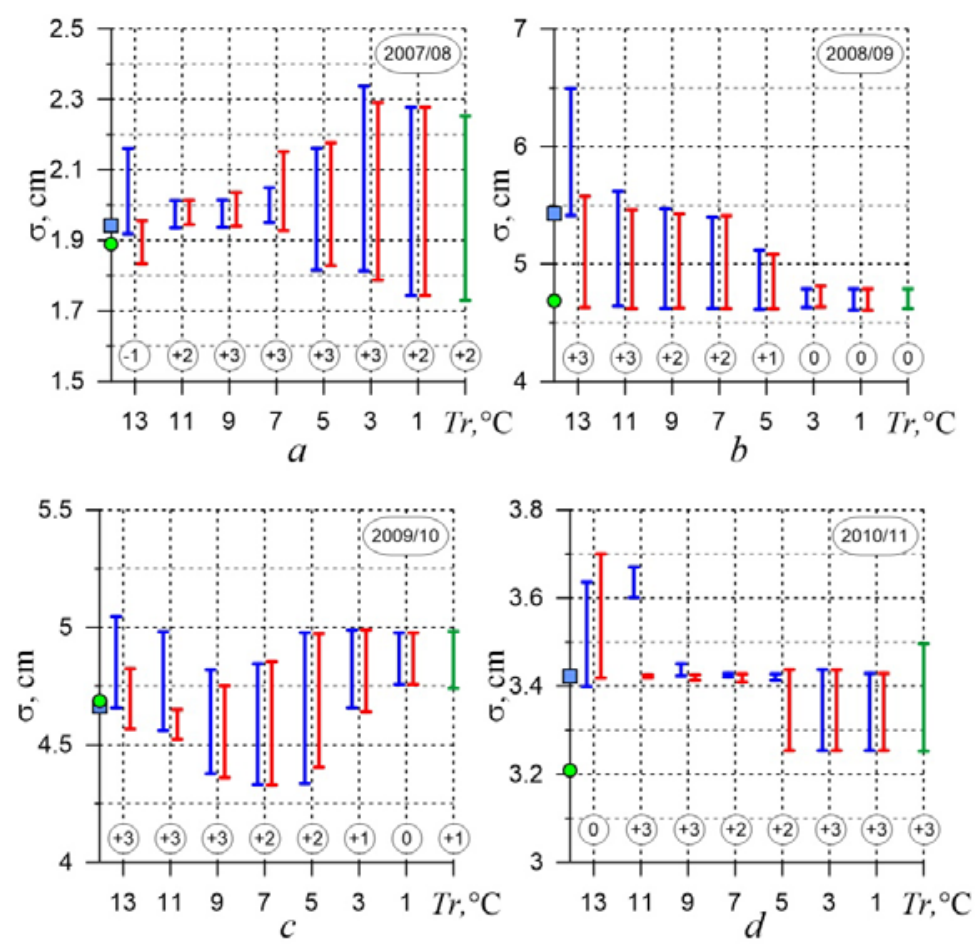

I - Variant 1 I - Variant 2 I - Variant 3 ロ - Variant 4 ○ - Variant 5

F i g. 3. Amplitude of the root-mean-square error $\sigma$ of the simulated ice thickness resulted from applying different dependences in determining a snow portion in atmospheric precipitation

The distributions of root-mean-square deviation $\sigma$ obtained in the calculations for the linear (variant 2) and S-like (variant 3) dependences of snow portion in atmospheric precipitation within the transition interval are shown in Fig. 4. The minimums of root-mean-square error are indicated in the figure by shaded circles.

From Fig. 3 and 4 it can be seen that for dry winters of 2007/08 and 2010/11 (the average computational snow height on the ice surface over a season did not exceed $0.5 \mathrm{~cm}$ ) a similar change in $\sigma$ was observed with varying widths of transition range $T r$ and temperature $T_{50}$. The highest sensitivity to $T_{50}$ selection was manifested both at large $\left(\operatorname{Tr}>11^{\circ} \mathrm{C}\right)$ and small $\left(\operatorname{Tr}<5^{\circ} \mathrm{C}\right) \operatorname{Tr}$ values. Smaller root-mean-square errors were obtained in calculations with a narrow transition range. With an increase in $\operatorname{Tr}$ width the error increased but its sensitivity to selection of temperature $T_{50}$ decreased. So, for $7-11^{\circ} \mathrm{C}$ range $T_{50}$ variation had little effect on $\sigma$. Note that the selection of threshold temperature in the static method must be carried out very carefully, since in this case there is not only the smallest root-mean-square deviation $\sigma_{\min }$ of all the considered variants but also close to the maximum amplitude $\sigma(T t)$. A similar character $\sigma$ behavior is probably explained by the fact that in the considered seasons contrasting weather conditions were observed [25, 26]. At generally relatively small amount of precipitation PHYSICAL OCEANOGRAPHY VOL. 27 ISS. 2 (2020) 
during these winter seasons, most of them fell in the form of rain (Fig. 2, $a, d$ ) when daily average temperature was noticeably higher than zero. Precipitation in the form of snow was observed during the periods of extensive cold air influxes, the temperature of which was significantly lower than the threshold temperature that varied within the indicated range.

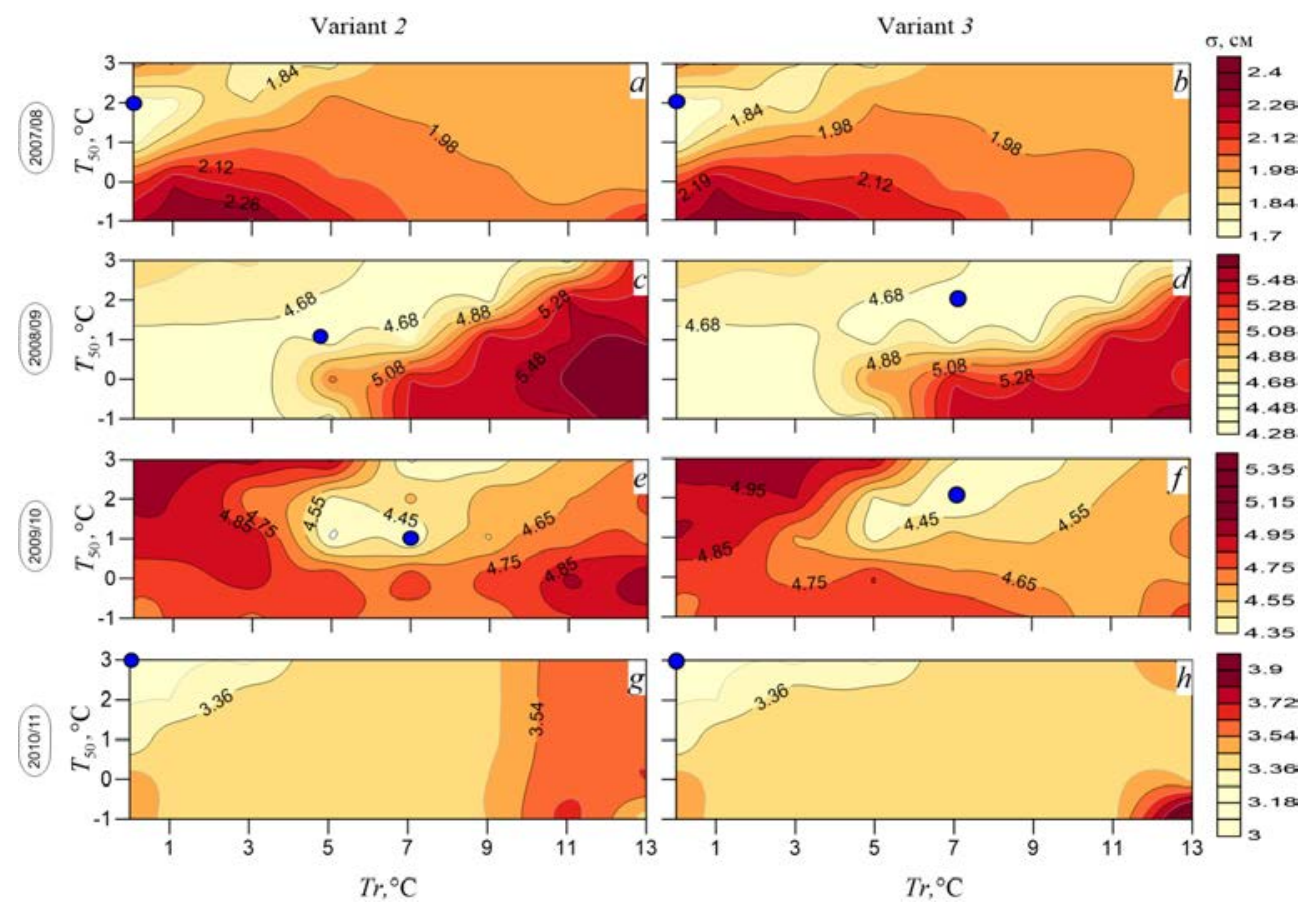

F i g. 4. Distribution of the root-mean-square error $\sigma$ for different values of temperature $T_{50}$ and width of the transition interval $T r$. The snow portion in atmospheric precipitation within the transition interval was defined using the linear (variant 2) and the S-like (variant 3 ) dependences $\operatorname{Pr}_{\text {snow }}\left(t_{\mathrm{a}}\right.$ )

The amount of precipitation that fell in 2008/09 and 2009/10 winter seasons on an ice-covered sea surface was significantly greater than in 2007/08 and 2010/11. Average over the season computational snow depth on ice amounted to $3 \mathrm{~cm}$ and $5.5 \mathrm{~cm}$ for 2008/09 and 2009/10, respectively. In addition, a significant part of the atmospheric precipitation (especially in the winter of 2009/10) occurred at air temperature in the transition range. The minimum root-mean-square error was obtained for $T_{50}$ close to $2{ }^{\circ} \mathrm{C}$ but, in contrast to dry winters, at wider transition range which amounted here to $5-9{ }^{\circ} \mathrm{C}$ (Fig. 3, b, c). The minimum $\sigma$ is most pronounced for the winter of $2009 / 10$ and slightly less noticeable for the winter of 2008/09 (Fig. 4, f, g). It should be noted that the use of S-like dependences $P r_{\text {snow }}\left(t_{\mathrm{a}}\right)$, in comparison to the linear transition from snow to rain, is more preferable, since the linear transition gives large calculation errors for small $\left(1-5{ }^{\circ} \mathrm{C}\right.$ width) and large (more than $7{ }^{\circ} \mathrm{C}$ width) transition ranges. 

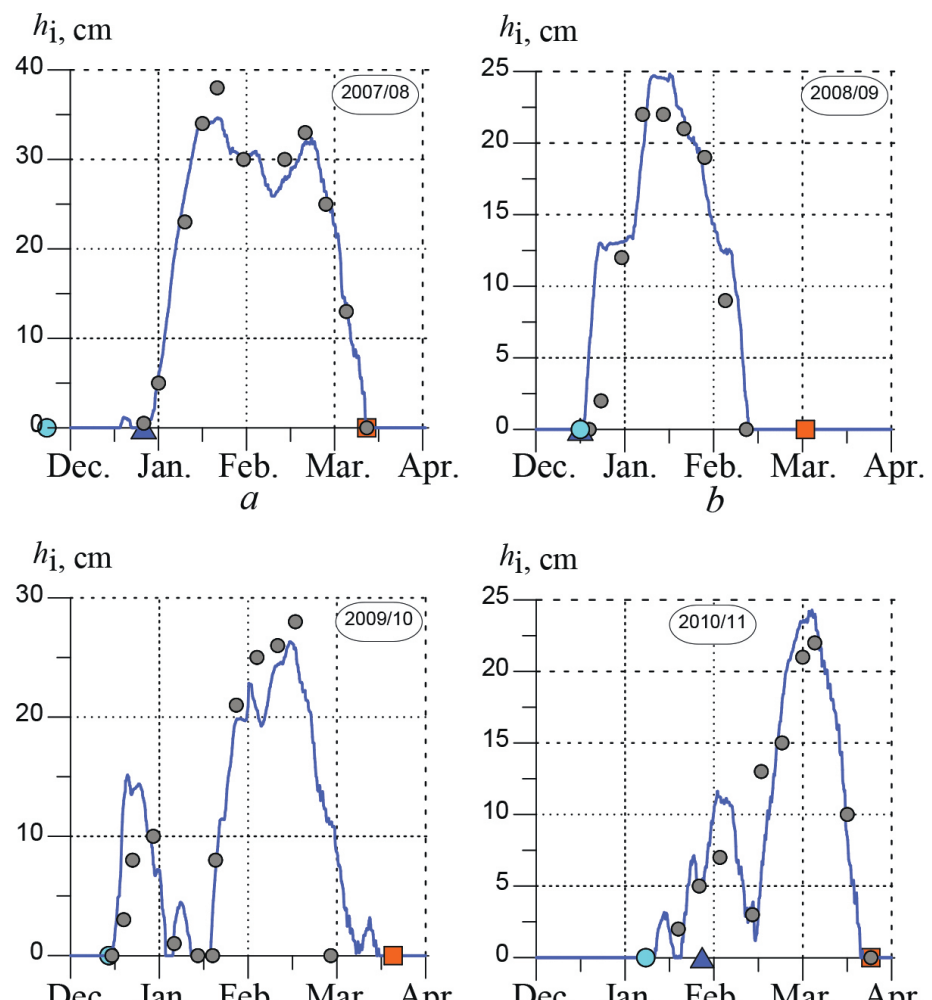

Dec. Jan. Feb. Mar. Apr.

$c$

Dec. Jan. Feb. Mar. Apr.

— - simulated ice thickness

- observed ice thickness (ESIMO)

0 - the first ice formation

$\Delta$ - starting of stable ice formation

$\square$ - final purification of ice

F i g. 5. Seasonal evolution of ice thickness based on the observation data and the simulation results: 2007/08 - variant $1, T t=2{ }^{\circ} \mathrm{C} ; 2008 / 09$ and $2009 / 10$ - variant $3, T_{50}=2{ }^{\circ} \mathrm{C}, \operatorname{Tr}=7{ }^{\circ} \mathrm{C} ; 2010 / 11-$ variant $1, T t=3^{\circ} \mathrm{C}$

The standard error of ice thickness forecast for variants 4, 5 is shown in Fig. 3 by filled squares and circles, respectively. The calculation results for these dependencies are close to each other but the forecast quality indicators for variant 5 are slightly better than for variant 4 . The results of the most successful model calculations of ice thickness thermodynamic evolution for 2007/08-2010/11 ice seasons are given in Fig. 5. In Table 2 the comparison of some calculation variants between themselves and with the data of field observations is presented. It should be noted that the number of ice thickness values taken from ESIMO maps is not enough for rigorous statistical analysis; therefore, the significance levels of the correlation coefficients are not given here. From Table 2 it can be seen that in dry winters $(2007 / 08,2010 / 11)$ the selection of static method (variant 1$)$ provides the best values of $\sigma$ and $K$. For winters with significant precipitation (2008/09, 2009/10) variant 3 , from the point of view of the obtained values of $\sigma, R^{2}$ и $U$, is 


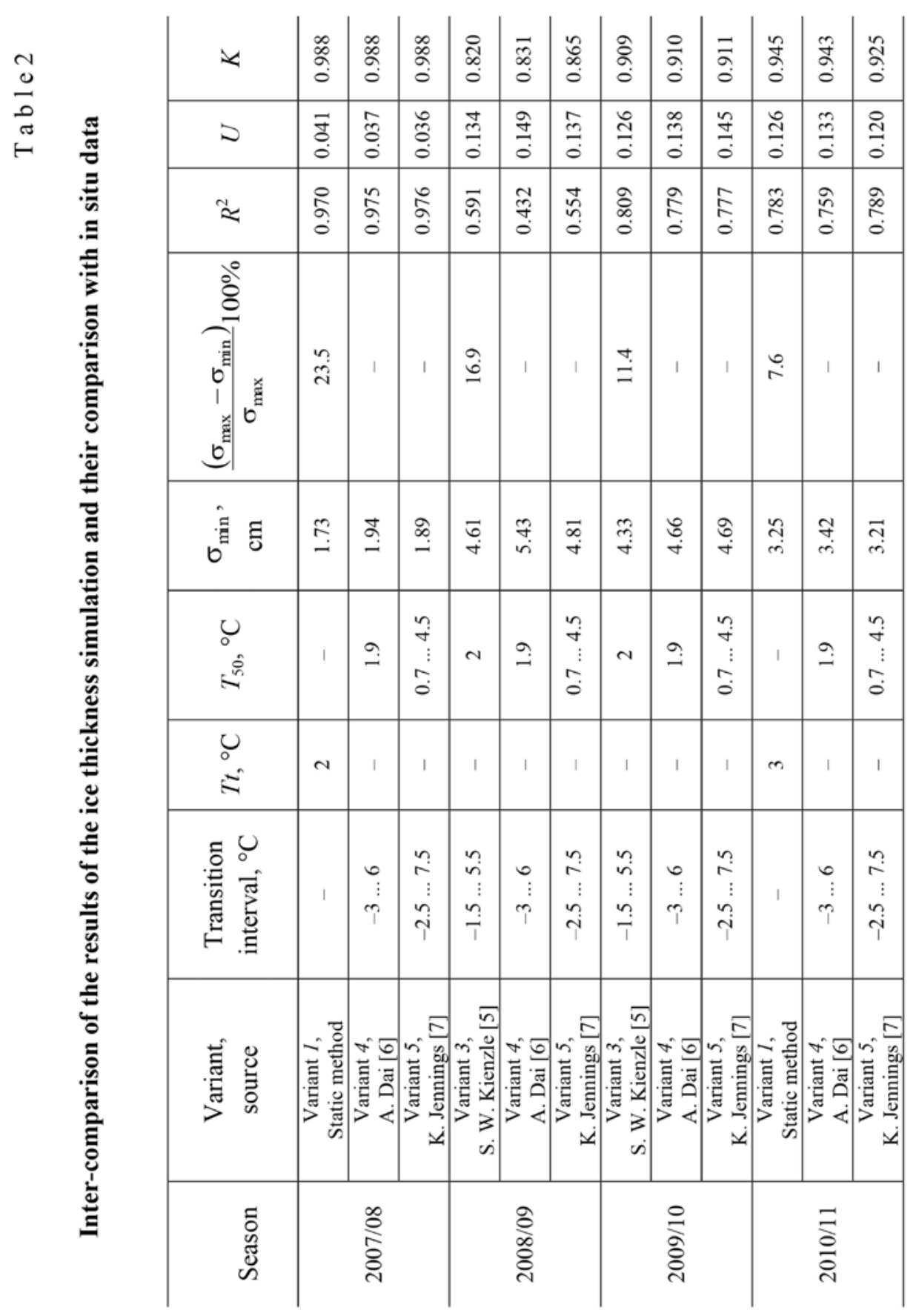


more preferable in comparison with other computational variants. In addition, the use of the dynamic method (version 5), regardless of the amount of precipitation in the ice period, allows one to obtain relatively high values of some criteria for assessing the forecast of the ice thickness seasonal variation: for dry winters these are $R^{2}$ and $U$ values and for snowy winters $-K$.

We point out that the regional climatic conditions and their variations in the current winter season have a significant impact on the threshold temperature and the transition range. Therefore, the question of determining universal regional dependence $\operatorname{Pr}_{\text {snow }}\left(t_{\mathrm{a}}\right)$ remains open. For a more detailed study of the of threshold temperature and transition range distribution, the data from specialized measurements of the precipitation phase composition over the studied sea surface are required.

\section{Conclusion}

The snow has high thermal insulation properties and therefore it has a significant effect on the seasonal variation of the sea ice thickness. When constructing a sea ice thermodynamic model, an adequate assessment of the snow cover thickness and determination of its thermophysical properties requires data both on the amount of precipitation and on their phase composition. In the Sea of Azov region, where a significant amount of mixed precipitation falls during the cold season, the selection of the criterion for their division into liquid and solid fractions can significantly affect the results of numerical modeling. A comparative analysis of the results of numerical experiments on reconstructing the seasonal variation of ice thickness and observational data at the Taganrog weather station in 2007/08-2010/11 winter seasons showed that from the point of view of optimal values of root-mean-square deviation and correlation coefficient the results obtained using the S-like dependence [5] of the snow fraction in atmospheric precipitation within the transition temperature range were the most justified. The smallest errors in reconstructing the ice thickness seasonal evolution were obtained at a threshold temperature close to $2{ }^{\circ} \mathrm{C}$ and transition temperature range width of $1 \ldots 3^{\circ} \mathrm{C}$ for dry winters and $5 \ldots 9^{\circ} \mathrm{C}$ for the winters with the amount of precipitation which is close to or exceeding the climatic norm. The calculations carried out using semi-empirical snow portion dependence on temperature and relative humidity yielded satisfactory results for all considered winter seasons. These dependences can be used in the absence of reliable data on the precipitation phase as the initial selection of precipitation separation method for applying in the sea ice thermodynamic model.

\section{REFERENCES}

1. Gershanovich, D.E., Goptarev, N.P., Zatuchnaya, B.M. and Simonov, A.I., 1991. [Hydrometeorology and Hydrochemistry of the Seas of the USSR. Volume 5. Sea of Azov]. Saint Petersburg: Gidrometeoizdat, 237 p.

2. Harpold, A.A., Kaplan, M.L., Klos, P.Z., Link, T., McNamara, J.P., Rajagopal, S., Schumer, R. and Steele, C.M., 2017. Rain or Snow: Hydrologic Processes, Observations, Prediction, and Research Needs. Hydrology and Earth System Sciences, 21(1), pp. 1-22. https://doi.org/10.5194/hess-21-1-2017 
3. Y Yang, Y., Leppäranta, M., Cheng, B. and Li, Z., 2016. Numerical Modelling of Snow and Ice Thicknesses in Lake Vanajavesi, Finland. Tellus A: Dynamic Meteorology and Oceanography, 64(1), 17202. https://doi.org/10.3402/tellusa.v64i0.17202

4. McCabe, G.J. and Wolock, D.M., 2010. Long-Term Variability in Northern Hemisphere Snow Cover and Associations with Warmer Winters. Climatic Change, 99(1-2), pp. 141-153. https://doi.org/10.1007/s10584-009-9675-2

5. Kienzle, S.W., 2008. A New Temperature Based Method to Separate Rain and Snow. Hydrological Processes, 22(26), pp. 5067-5085. https://doi.org/10.1002/hyp.7131

6. Dai, A., 2008. Temperature and Pressure Dependence of the Rain-Snow Phase Transition over Land and Ocean. Geophysical Research Letters, 35(12), L12802. https://doi.org/10.1029/2008GL033295

7. Jennings, K.S., Winchell, T.S., Livneh, B. and Molotch, N.P., 2018. Spatial Variation of the Rain-Snow Temperature Threshold across the Northern Hemisphere. Nature Communications, 9, 1148. doi:10.1038/s41467-018-03629-7

8. Ivanov, B.V. and Makshtas, A.P., 1990. [Quasistationary Zero-Dimensional Model of Arctic Ice]. In: AARI, 1990. Trudy Arkticheskogo i Antarkticheskogo Nauchno-Issledovatel'skogo Instituta [Proceedings of AARI]. Issue 420, pp. 18-31 (in Russian).

9. Yakovlev, N.G., 2009. Reproduction of the Large-Scale State of Water and Sea Ice in the Arctic Ocean from 1948 to 2002: Part II. The State of Ice and Snow Cover. Izvestiya, Atmospheric and Oceanic Physics, 45(4), pp. 478-494. doi:10.1134/S0001433809040082

10. Kulakov, M.Yu., Makshtas, A.P. and Shutilin, S.V., 2012. AARI-IOCM - Coupled ICEOCEAN Circulation Model for the Arctic Ocean. Problemy Arktiki i Antarktiki = Arctic and Antarctic Research, 2(92), pp. 6-18 (in Russian).

11. Klyachkin, S.V., Guzenko, R.B. and May, R.I., 2015. Numerical Model of the Ice Cover Evolution in Arctic Seas for the Operational Forecasting. Ice and Snow, 55(3), pp. 83-96 (in Russian). doi:10.15356/2076-6734-2015-3-83-96

12. Zavyalov, D.D., 2019. Reconstruction of the Ice Thickness Seasonal Evolution in the Northeastern Sea of Azov Using Different Arrays of Meteorological Data. Physical Oceanography, 26(3) pp. 247-259. doi:10.22449/1573-160X-2019-3-247-259

13. Roeckner, E., Bäuml, G., Bonaventura, L., Brokopf, R., Esch, M., Giorgetta, M., Hagemann, S., Kirchner, I., Kornblueh, L., Manzini, E., Rhodin, A., Schlese, U., Schulzweida, U. and Tompkins, A., 2003. The Atmospheric General Circulation Model ECHAM-5: Part 1. Model Description. Hamburg, Germany: Max-Planck-Institut für Meteorologie. Report No. 349, 140 p. Available at: https://www.researchgate.net/publication/247784697_The_atmospheric_general_circulation_ model_ECHAM5 [Accessed: 5 June 2018].

14. Hunke, E.C. and Lipscomb, W.H., 2010. CICE: The Los Alamos Sea Ice Model Documentation and Software User's Manual Version 4.1. Los Alamos: Los Alamos National Laboratory, 76 p. Available at: https://clck.ru/MM2E6 [Accessed 5 January 2020].

15. Zav'yalov, D.D. and Solomakha, T.A., 2019. Snow Cover Influence on Sea Ice in the Taganrog Bay. Russian Meteorology and Hydrology, 44(1), pp. 45-52. doi:10.3103/S1068373919010059

16. Bartlett, P.A., MacKay, M.D. and Verseghy, D.L., 2006. Modified Snow Algorithms in the Canadian Land Surface Scheme: Model Runs and Sensitivity Analysis at Three Boreal Forest Stands. Atmosphere-Ocean, 44(3), pp. 207-222. doi:10.3137/ao.440301

17. Lecomte, O., Fichefet, T., Vancoppenolle, M. and Nicolaus, M., 2011. A New Snow Thermodynamic Scheme for Large-Scale Sea-Ice Models. Annals of Glaciology, 52(57), pp. 337-346. doi:10.3189/172756411795931453

18. Kuz'min, P.P., 1957. Physical Properties of the Snow Cover. Leningrad: Gidrometeoizdat, 179 p. (in Russian).

19. Osokin, N.I., Sosnovskiy, A.V. and Chernov, R.A., 2017. Effective Thermal Conductivity of Snow and Its Variations. Earth's Cryosphere, 21(3), pp. 55-61. doi:10.21782/EC2541-99942017-3(55-61) 
20. Chizhov, A.N., 1990. [Formation of the Ice Cover and the Spatial Distribution of Its Thickness]. Leningrad: Gidrometeoizdat, 126 p. (in Russian).

21. Bogorodskii, P.V. and Pnyushkov, A.V., 2011. Influence of Melt Ponds on the Formation of the Multiyear Sea Ice Cover. Oceanology, 51(2), pp. 213-220. doi:10.1134/S0001437011020020

22. Makshtas, A.P., Bogorodskiy, P.V. and Kustov, V.Yu., 2012. Rapid Melt of Land Fast-Ice in Sogo Bay (Tiksi Gulf) during Spring 2011. Problemy Arktiki $i$ Antarktiki = Arctic and Antarctic Research, 1(91), pp. 37-47 (in Russian).

23. D'yakov, N.N., Timoshenko, T.Yu., Belogudov, A.A. and Gorbach, S.B., 2015. [Ice Atlas of the Black and Azov Seas]. Sevastopol: ECOSY-Gidrofizika, 219 p. (in Russian).

24. Matishov, G., Matishov, D., Gargopa, Y., Dashkevich, L., Berdnikov, S., Kulygin, V., Arkhipova, O, Chikin, A., Shabas, I., Baranova, O. and Smolyar, I., 2008. Climatic Atlas of the Sea of Azov 2008. NOAA Atlas NESDIS 65. Washington: U.S. Government Printing Office, 148 p. CD-ROM.

25. Fedorenko, A.V., 2009. [Features of the Ice Season 2007-2008 on the Sea of Azov]. In: Hydrometcentre of Russia, 2009. Proceedings of Hydrometcentre of Russia. Issue 343, pp. 79-88 (in Russian).

26. Matishov, G.G., Chikin, A.L., Dashkevich, L.V., Kulygin, V.V. and Chikina, L.G., 2014. The Ice Regime of the Sea of Azov and Climate in the Early 21st Century. Doklady Earth Sciences, 457(2), pp. 1020-1024. doi:10.1134/S1028334X14080133

About the author:

Dmitry D. Zavyalov, Senior Research Associate, Marine Hydrophysical Institute of RAS (2 Kapitanskaya St., Sevastopol, 299011, Russian Federation), Ph. D. (Phys.-Math.), Scopus Author ID: 6506347014, ORCID ID: 0000-0002-7444-980X, zavyalov.dd@mhi-ras.ru

The author has read and approved the final manuscript.

The author declares that he has no conflict of interest. 